\title{
Melatonin Prevents Brain Damage and Neurocognitive Impairment Induced by Plasmodium Berghei ANKA Infection in Murine Model of Cerebral Malaria
}

\author{
Brenda Jaqueline de Azevedo Ataide ${ }^{1}$, Nayara Kauffmann ${ }^{1}$, \\ Nívia de Souza Franco Mendes ${ }^{1}$, Marjorie Lujan Marques Torres ${ }^{1,2}$, \\ Larissa Medeiros dos Anjos ${ }^{1,2}$, Adelaide da Conceição Fonseca Passos ${ }^{1}$, \\ Suellen Alessandra Soares de Moraes ${ }^{1}$, Evander de Jesus Oliveira Batista ${ }^{2}$, \\ Anderson Manoel Herculano ${ }^{1}$ and Karen Renata Herculano Matos Oliveira ${ }^{1 *}$ \\ ${ }^{1}$ Laboratory of Experimental Neuropharmacology, Biological Science Institute, UFPa, Belém, Brazil, ${ }^{2}$ Laboratory of \\ Protozoology, Topical Medicine Nucleus, UFPa, Belém, Brazil
}

OPEN ACCESS

Edited by:

Philippe E. Van Den Steen,

KU Leuven, Belgium

Reviewed by:

Renato Augusto DaMatta,

State University of the North

Fluminense Darcy Ribeiro, Brazil

Martha Legorreta-Herrera,

National Autonomous University of

Mexico, Mexico

*Correspondence:

Karen Renata Herculano Matos

Oliveira

oliveirakrm@gmail.com; karen@ufpa.br

Specialty section:

This article was submitted to

Parasite and Host,

a section of the journa

Frontiers in Cellular and Infection

Microbiology

Received: 09 March 2020

Accepted: 18 August 2020

Published: 30 September 2020

Citation:

Ataide BJdA, Kauffmann N, Mendes NdSF, Torres MLM, dos

Anjos LM, Passos AdCF, de

Moraes SAS, Batista EdJO,

Herculano AM and Oliveira KRHM

(2020) Melatonin Prevents Brain

Damage and Neurocognitive

Impairment Induced by Plasmodium

Berghei ANKA Infection in Murine

Model of Cerebral Malaria.

Front. Cell. Infect. Microbiol.

10:541624

doi: $10.3389 /$ fcimb.2020.541624
Cerebral malaria is characterized by permanent cognitive impairments in Plasmodium-infected children. Antimalarial therapies show little effectiveness to avoid neurological deficits and brain tissue alterations elicited by severe malaria. Melatonin is a well-recognized endogenous hormone involved in the control of brain functions and maintenance of blood-brain barrier integrity. The current study has evaluated the effect of melatonin on the histological alterations, blood-brain barrier leakage, and neurocognitive impairments in mice developing cerebral malaria. Swiss mice infected with Plasmodium berghei ANKA strain was used as cerebral malaria model. Melatonin treatment (5 and $10 \mathrm{mg} / \mathrm{kg}$ ) was performed for four consecutive days after the infection, and data have shown an increased survival rate in infected mice treated with melatonin. It was also observed that melatonin treatment blocked brain edema and prevented the breakdown of blood-brain barrier induced by the Plasmodium infection. Furthermore, hematoxylin and eosin staining revealed that melatonin mitigates the histological alterations in Plasmodium-infected animals. Melatonin was also able to prevent motor and cognitive impairments in infected mice. Taken together, these results show for the first time that melatonin treatment prevents histological brain damages and neurocognitive alterations induced by cerebral malaria.

Keywords: cerebral malaria, melatonin, blood-brain barrier, neurobehavioral impairment, Plasmodium

\section{INTRODUCTION}

Malaria is a potentially life-threatening disease affecting an estimated 207 million people each year (WHO, 2017). Majority of the fatal cases were due to cerebral malaria (CM), which is the most severe neurological complication of Plasmodium falciparum infection that affects mainly children under 5 years of age (WHO, 2000; Idro et al., 2005). Major clinical symptoms of CM include dyspnea, fever, sudden bleeding, disorientation, convulsions, coma, and death. CM survivors could 
exhibit long-term neurocognitive impairments such as cortical blindness, hearing loss, ataxia, and memory and attention disorders, which is partly due to the fact that antimalarial drugs do not prevent the damages in the central nervous system (CNS) parenchyma (John et al., 2008; Rénia et al., 2012). The mechanism of CM-induced brain injuries is still not fully understood. However, previous studies reveal that increased cytoadherence of parasitized red blood cells ( $\mathrm{pRBC}$ ) leads to brain microvascular obstruction, hypoxia state, and consequent damage of the brain structures. Data from literature also describe the role of proinflammatory cytokines, microglial activation, and oxidative stress on the pathogenicity of CM (Hunt and Grau, 2003).

Most of these neuropathological mechanisms associated with $\mathrm{CM}$ were clarified utilizing animal models that simulate the clinical signals described in humans developing CM. Experimental cerebral malaria (ECM) can be developed by using the rodent malaria model with the infection of susceptible mouse strains as $\mathrm{C} 57 \mathrm{BL} / 6$ and Swiss albino mice with Plasmodium berghei ANKA parasites (Combes et al., 2005; Martins et al., 2009a,b). The mouse model exhibit several of the neurological features of human cerebral malaria (HCM) such as brain neuroinflammation (Hunt and Grau, 2003), reduced cerebral blood flow, blood-brain barrier (BBB) disruption, microhemorrhages (Hunt et al., 2006), brain swelling, and neurological impairment (Desruisseaux et al., 2008; Dai et al., 2010). In this context, the use of endogenous compounds with recognized ability to protect CNS parenchyma could exert significant protection against the brain damage and cognitive impairments evoked by CM.

Melatonin (N-acetyl-5-methoxytryptamine) is an endogenous neuro-hormone primarily synthesized and released from the pineal gland of mammals during the dark phase of the lightdark cycle (Rodriguez et al., 2004). In addition to the pineal gland, melatonin could be released at several extrapineal sites at the CNS, including hypothalamus, cerebellum, retina, nucleus gracilis, medulla oblongata, and cerebral cortex, modulating several neurophysiological roles (Jimenez-Jorge et al., 2007; Radogna et al., 2010). Furthermore, previous studies also describe that melatonin could act as a neuroprotective molecule in both acute brain injuries as cerebral ischemia and chronic neurodegenerative conditions such as Alzheimer and Huntington disease (Wang et al., 2011; Rudnitskaya et al., 2015). Moreover, melatonin could effectively reduce brain inflammation by inhibiting nuclear factor kappa B (NF- $\mathrm{B})$ translocation and matrix metallopeptidase-9 (MMP-9) activation in lipopolysaccharide (LPS)-induced inflammation in both in vivo and in vitro experimental models (Chang et al., 2012). This indoleamine is also effective in reducing oxidative stress by increasing the activity and expression of several antioxidant enzymes such as superoxide dismutase, catalase, and glutathione peroxidase (Fischer et al., 2013; Zhang and Zhang, 2014). Melatonin has been implicated in cognitive events as learning process and memory formation as well as ameliorating motor coordination after brain injuries (He et al., 2013; Bavithra et al., 2017). In the rat model of hypoxia-ischemia, melatonin treatment efficiently decreases brain damage by the modulation of BBB integrity.

Recently, a report also demonstrated that melatonin treatment could modulate the progression of infectious disease such as amoebiasis, leishmaniasis, and trypanosomiasis (Daryani et al., 2018). During a rat chronic infection with Trypanosoma cruzi, melatonin attenuates oxidative stress condition and the inflammatory process by decreasing nitric oxide and lipid peroxidation and raising the release of interleukin-17A (Brazão et al., 2015).

In malaria infection, melatonin displays a controversial role in the growth and development of some Plasmodium species. It has been described that endogenous melatonin modulates the parasite life cycle and maintain the synchronicity of Plasmodium falciparum and Plasmodium chabaudi, which assure the propagation of the infection in the host (Beraldo et al., 2005; Budu et al., 2007). In spite of that, a previous study showed that melatonin does not synchronize experimental malaria infection caused by Plasmodium berghei and Plasmodium yoelii (Bagnaresi et al., 2009). Recent studies have demonstrated that melatoninderived synthetic indoles, which modulate the activation of melatonin receptors, inhibited in vitro $P$. falciparum growth at lower concentrations (Schuck et al., 2014; Luthra et al., 2019), emerging as new alternative therapeutic approach to alter disease progression. Little is known about the effect of melatonin in the host infected with Plasmodium, which mainly concerns the cerebral impairment elicited by the disease.

Taken together, all of these findings prompted us to ask if melatonin treatment is able to modulate the progression of the disease by preventing histological alteration and neurocognitive impairments elicited by CM in mice.

\section{MATERIALS AND METHODS}

\section{Experimental Animals}

Male Swiss albino mice 5-6 weeks old (weighing 20-24 g) were obtained from the Animal Care Facilities of the Institute of Biological Science, Federal University of Para (Belem-Brazil). Mice were maintained in polypropylene cages (five mice per cage) under standard and controlled conditions of temperature $(24 \pm$ $\left.1^{\circ} \mathrm{C}\right)$ and humidity $(55 \pm 10 \%)$. Filtered water and standard pellet diet were given ad libitum.

\section{Plasmodium Berghei ANKA Infection}

Infection was performed as previously described by Oliveira et al. (2017). Plasmodium berghei ANKA (PbA) strains (Laboratory of Experimental Neuropharmacology, UFPa) were kept as frozen stocks in liquid nitrogen vials. Briefly, all experimental mice were intraperitoneally (i.p.) infected with $1 \times 10^{6} \mathrm{PbA}-\mathrm{pRBCs}$ suspended in $0.1 \mathrm{ml}$ of phosphate-buffered saline (PBS), obtained from cardiac puncture from homolog mice that had been previously injected with frozen $\mathrm{PbA}$ stock solution.

In the course of the disease, mice were observed for parameters as weight loss, survival, blood parasitemia, and ECM clinical signs. Infected and treated animals were assessed daily, and the time of death was promptly registered. Behavioral 
changes, such as ataxia and convulsion state, were used as established humane endpoints to reduce animal suffering.

Animal body weights were regularly measured during the course of the disease. Parasitemia levels (percentage of pRBCs) were monitored daily by microscopic counting from Giemsastained (Sigma-Aldrich) thin smears obtained from mice tail-vein blood and determined according to the formula [(number of $\mathrm{pRBCs}) /($ total numbers of RBCs counted)] $\times 100$.

\section{Melatonin Treatment}

To evaluate the potential neuroprotective effect of melatonin in ECM, mice were randomly assigned into four distinct groups: uninfected control group, $\mathrm{PbA}$-infected group and $\mathrm{PbA}$-infected and treated with $5 \mathrm{mg} / \mathrm{kg}$ melatonin, and $\mathrm{PbA}$-infected and treated with $10 \mathrm{mg} / \mathrm{kg}$ melatonin. Melatonin (Sigma-Aldrich) dissolved in 1\% DMSO (Sigma-Aldrich, Brazil) solution and saline $(0.9 \%$; $\mathrm{pH} 7.4)$ was given by intraperitoneal injection once daily at a dose of 5 and $10 \mathrm{mg} / \mathrm{kg}$ for four consecutive days post-infection, starting on the day of infection. Mice of the control group and $\mathrm{PbA}$-infected group received (i.p.) $0.9 \%$ saline solution daily.

\section{Rapid Murine Coma and Behavior Tests}

At day 6 post-infection, the behavioral clinical signs and disease severity was monitored using the grading quantitative Rapid Murine Coma and Behavior scale (RMCBS) described by Carroll et al. (2010). This method was developed to assess the early clinical manifestation of murine CM, and the protocol consists of 10 parameters in which hygiene-related behavior gait, body position, exploratory behavior, and balance were assessed and scored from 0 to 20 , in which 0 corresponds to the lowest compromised neurological function and 20 corresponds to severe neurological impairment.

Briefly, in $3 \mathrm{~min}$, the animals were subjected to a video recording for $90 \mathrm{~s}$ to assess behavioral parameters such as gait, motor performance, body position, touch escape, pinna reflex, toe pinch, aggression, and grooming. In the next $90 \mathrm{~s}$, mice were assessed for limb strength and balance. Each parameter was scored 0-2 points based on the performance of the infected and treated mice, in which 0 corresponds to severe neurological impairment and 2 corresponds to the lowest compromised neurological function. The total score $(0-20)$ of the domains was calculated by the sum of the parameters for each animal on day of analysis.

\section{Evans Blue Dye Perfusion for Vascular Leakage}

BBB disruption was assessed by measuring Evan's blue extravasation as previously described by Kim et al. (2014). Briefly, at day 6 post-infection, mice were intraperitoneally injected with $200 \mu \mathrm{l}$ of $1 \%$ Evan's blue dye (Sigma-Aldrich) prepared in sterile saline solution. After $2 \mathrm{~h}$, anesthetized mice were perfused with saline and sacrificed. Brains were isolated, weighed, and placed in dimethyl formamide for $48 \mathrm{~h}$ at $37^{\circ} \mathrm{C}$ (in the dark) to extract Evan's blue dye from the brain tissue. The concentration of Evan's Blue dye was measured at $620 \mathrm{~nm}$ in a plate reader and calculated using a standard dye curve. Data were expressed as micrograms of dye extravasated per gram of brain tissue.

\section{Edema}

Brain water content as a marker of cerebral edema was determined using the wet/dry method previously described by Ding et al. (2015). At 6 days post-infection, mice were deeply anesthetized and brains were collected and immediately weighted (wet weight) and then dried at $80^{\circ} \mathrm{C}$ for $72 \mathrm{~h}$ (dry weight). The percentage of brain water content was then estimated as [(wet weight - dry weight)/wet weight $\times 100 \%$ ].

\section{Hematoxylin and Eosin Staining and Cell Counting}

Mice were first anesthetized with ketamine and xylazine, and the brains of each experimental group were transcardially perfused with PBS and 4\% paraformaldehyde. Post-fixed brains were carefully dissected and embedded in paraffin wax. Serial coronal sections into $8 \mu \mathrm{m}$ were performed and stained with hematoxylin and eosin (H\&E). The brain cortex was examined in the corticalmedullary area under a light microscope and photographed at 20,40 , and $60 \times$ objective lens. For cell counting, DAPI $(4,6-$ diamidino-2-phenylindole; Sigma) staining was performed as previously described (Chan et al., 2012). In brief, the freefloating sections were washed with PBS and incubated with DAPI solution $(1: 10,000)$ for nuclear staining at $37^{\circ} \mathrm{C}$ for $2 \mathrm{~min}$. To count the cell nucleus, slices were placed in mounting medium (Fluoroshield) and visualized under fluorescence microscopy ( 220 objective lens); (Nikon_EclipseNi). To assure the counting of cells from cerebral parenchyma, areas of cell infiltrate were excluded from DAPI counting. Data were analyzed using ImageJ software.

\section{Open Field Behavior Test}

The open field is a common test used to measure mice locomotor and exploratory behavior. The test was performed 6 days postinfection according to the protocol described by Desruisseaux et al. (2008). Briefly, mice were individually placed in the center of the testing chamber $(83 \times 52 \mathrm{~cm})$ with black floor to freely explore the arena for $5 \mathrm{~min}$. Data recorded included the number of crossed quadrants, grooming frequency, and lifting frequency. Each animal performed only one trial test. The apparatus was cleaned with $70 \%$ alcohol between trials, and tests were carried out under the same standard conditions. The sessions were monitored by a digital camera attached above the apparatus, and later analyses were conducted using the X-Plot-Rat Software.

\section{Statistical Analysis}

All data were expressed as the mean \pm standard deviation (SD). Statistical analyses were performed using one-way ANOVA followed by post-test Tukey-Kramer. Survival data were compared and analyzed using log-rank test of Kaplan-Meier curves. Mice were randomly divided into groups of 10 animals (per group), and all data are representative of at least two independent experiments. Analyses were conducted with the GraphPad Prism Software and significant differences were defined with $p$ values below 0.05 . 


\section{RESULTS}

\section{Melatonin Treatment Improves the Survival Rate and Disease Severity in Swiss Mice Infected With PbA}

To address the effect of melatonin on the clinical progression of ECM, PbA-infected mice were treated with 5 and $10 \mathrm{mg} / \mathrm{kg} / \mathrm{day}$ of melatonin for four consecutive days. Consistent with prior observations, $\mathrm{PbA}$-infected mice developed marked neurological symptoms between 6 and 10 days post-infection, characterized by physical inactivity, hemiplegia, and ataxia ending up with convulsions, coma, and death. Eighty percent of $\mathrm{PbA}$-infected mice succumbed to $\mathrm{CM}$ on days $8-11$ whereas $20 \%$ died on day 15 due to severe malaria (Figure 1A). Despite having no anti-parasitic action, melatonin treatment in both doses of 5 and $10 \mathrm{mg} / \mathrm{kg}$ significantly prolonged the survival rate of
$\mathrm{PbA}$-infected mice. At 11 days post-infection, the melatonintreated group exhibited a $57 \%$ of survival rate with mice showing no $\mathrm{CM}$ neurological symptoms when compared to the $\mathrm{PbA}$ infected group that exhibited a 16\% survival rate (Figure 1A). To investigate whether the survival improvement was correlated to changes in peripheric parasite rate, parasitemia was monitored, but no significant difference was registered between groups (Figure 1B). Further, melatonin also had no effect on body weight average in uninfected mice or in $\mathrm{PbA}$-infected mice (Figure 1C).

In the RMCBS protocol, melatonin treatment also reduced disease severity and the development of neurological signs associated to ECM. It was possible to notice that melatonin treatment at both 5 and $10 \mathrm{mg} / \mathrm{kg}$ prevented the loss of all functional domains evaluated in the late stage of the disease

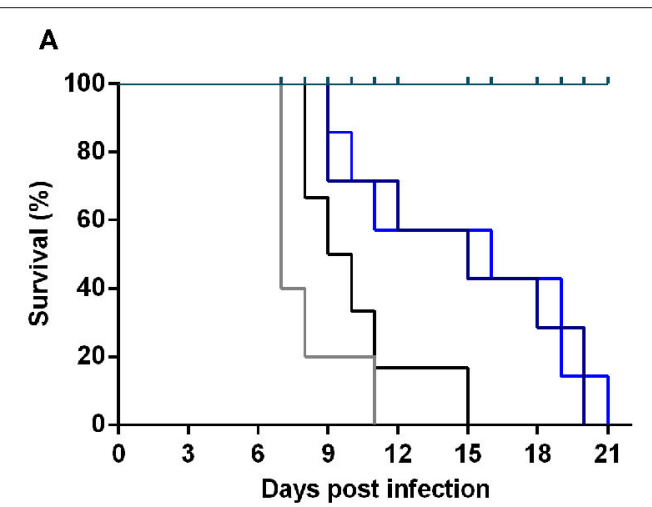

C

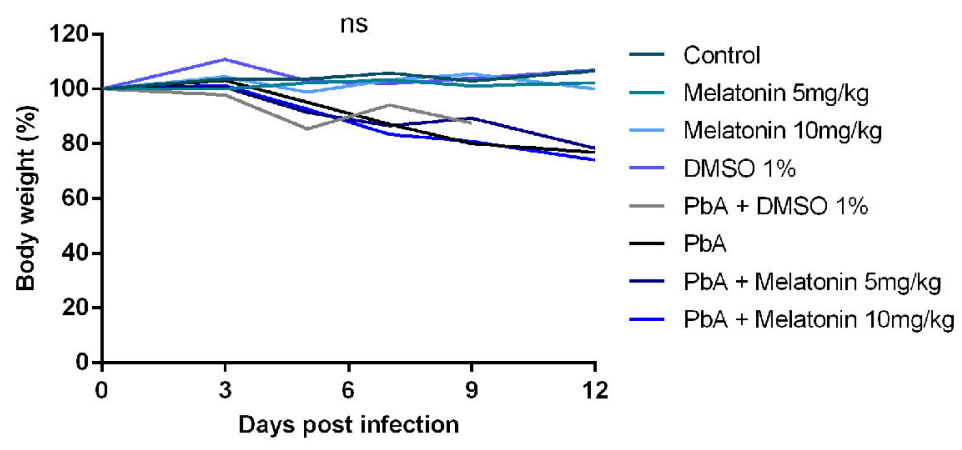

\section{+ Control \\ + Melatonin $5 \mathrm{mg} / \mathrm{kg}$}

+ Melatonin $10 \mathrm{mg} / \mathrm{kg}$

- DMSO $1 \%$

$+\mathrm{PbA}+\mathrm{DMSO} 1 \%$

$+\mathrm{PbA}$

- $\mathrm{PbA}+$ Melatonin $5 \mathrm{mg} / \mathrm{kg}$

— $\mathrm{PbA}+$ Melatonin $10 \mathrm{mg} / \mathrm{kg}$

B

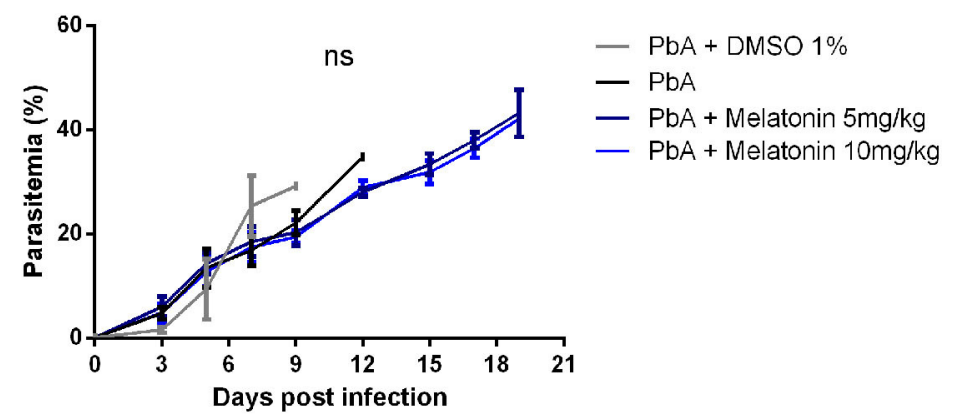

FIGURE 1 | Melatonin prolonged survival of Plasmodium berghei-infected mice. Plasmodium berghei ANKA (PbA)-infected mice were treated intraperitoneally from day 1 to day 4 post-infection with melatonin at 5 and $10 \mathrm{mg} / \mathrm{kg} /$ day. (A) Survival curve improved after melatonin treatment compared to saline PbA-infected group ( $p$ $\leq 0.05$, log rank test). (B) Parasitemia curve did not differ significantly between groups. Parasitemia levels were measured as the number of parasitized red blood cells (pRBCs) in at least 1,000 RBCs (ns, not significant). (C) Body weight variation during the infection (\%). The results are representative of three independent infections; $n=10$ animals/group. Results shown are mean \pm SD. 
(day 6 post-infection) such as coordination, motor performance, muscle tone and strength, reflexes and self-preservation, and hygiene-related behavior (Figure 2).

\section{Melatonin Prevents BBB Disruption and Cerebral Edema Induced by $\mathrm{PbA}$ Infection}

We next investigated whether brains of melatonin-treated mice showed differences in the stability of the $\mathrm{BBB}$, once its disruption is a crucial event associated with human and experimental CM outcome (de Souza et al., 2009). The effect of melatonin in BBB permeability was evaluated by determining the Evans blue dye concentrations in the mice brain tissue. Figure $3 \mathbf{A}$ shows representative images of whole brains in the distinct groups, revealing that melatonin-treated $\mathrm{PbA}$-infected mice had a more discrete staining when compared to the $\mathrm{PbA}$-infected group.

The quantification of formamide extraction revealed that the brains of CM mice had a marked increased in BBB permeability at 6 days post-infection (an average increase of $40 \%$ in Evans blue extravasation as compared to uninfected control group-from
$8 \mu \mathrm{g} / \mathrm{g}$ in uninfected control to $40 \mu \mathrm{g} / \mathrm{g}$ in $\mathrm{PbA}$-infected mice) (Figure 3B). In contrast, melatonin-treated $\mathrm{PbA}$-infected mice in both doses of 5 and $10 \mathrm{mg} / \mathrm{kg}$ exhibited a dramatically reduced amount of Evans blue extravasated into the brain parenchyma when compared to PbA-infected mice (Figure 3B).

As shown in Figure 4, brain water content was also evaluated at day 6 post-infection as an indicator of brain edema. It was demonstrated that $\mathrm{PbA}$ infection significantly increased brain water content when compared to the uninfected mice group. However, melatonin-treated $\mathrm{PbA}$-infected mice had significantly less brain water content than the $\mathrm{PbA}$-infected group. This result indicates that melatonin ameliorates the brain edema induced by $\mathrm{PbA}$ infection.

\section{Melatonin Decreases Histological Alterations in PbA-Infected Animals}

Histological analysis of brain cortical slices showed a disorganized parenchyma with evident acidophilic nuclear retraction and vacuolation at 6 days post-infection. Cellular
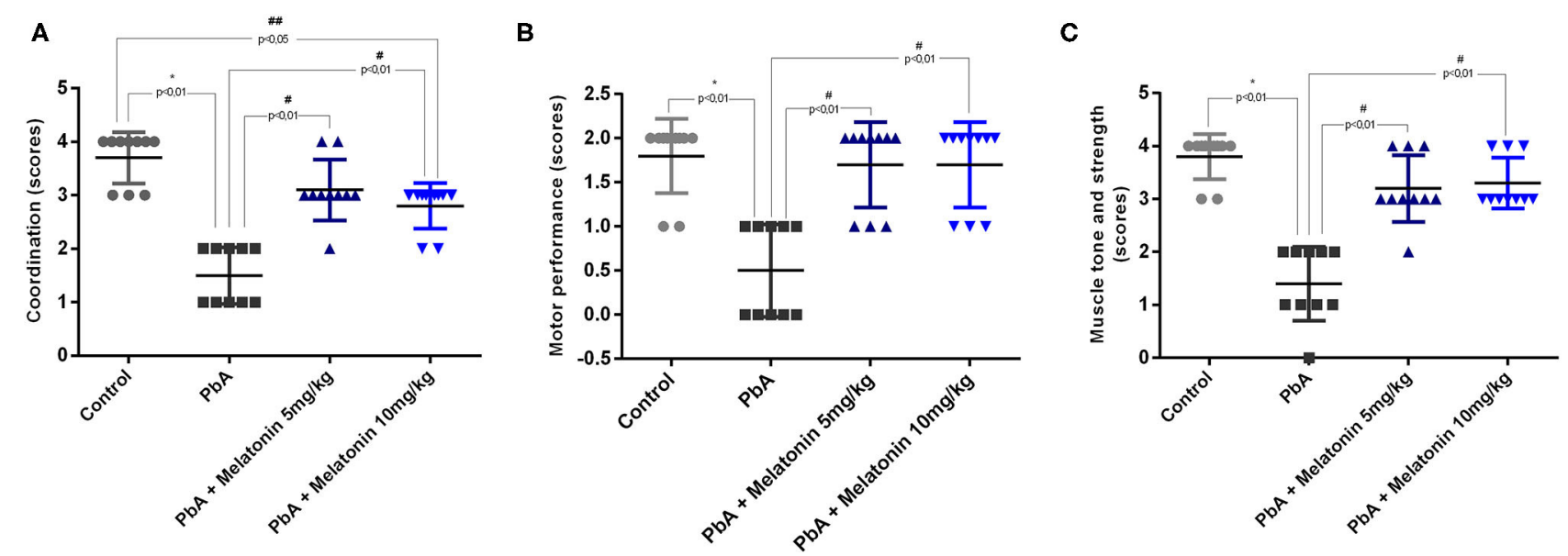

D

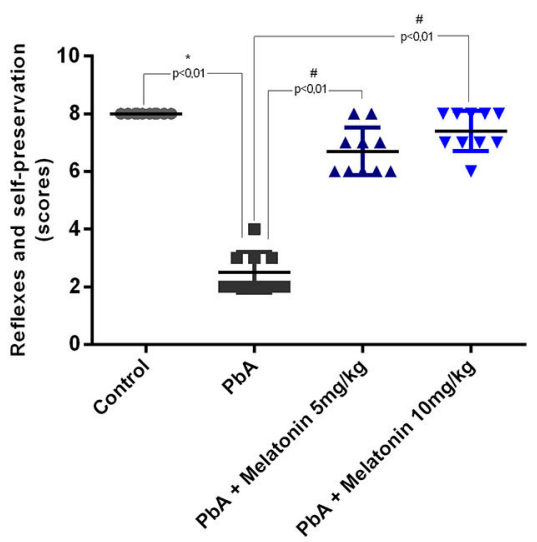

E

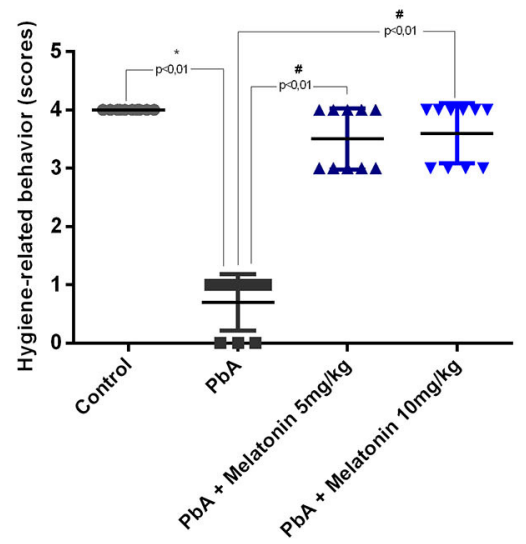

FIGURE 2 | Neurological signs based on RMCBS were significantly reduced in PbA-infected mice at 6 days post-infection. Melatonin treatment improves all the parameters analyzed as coordinating (A), locomotion (B), strength and muscle tone (C), self-preservation (D), and grooming (E); $n=10$ animals/group. Data are presented as average \pm SD. ${ }^{*} p<0.01$ vs control; ${ }^{*} p<0.01$ vs PbA; ${ }^{\# \#} p<0.05$ vs PbA. 
A
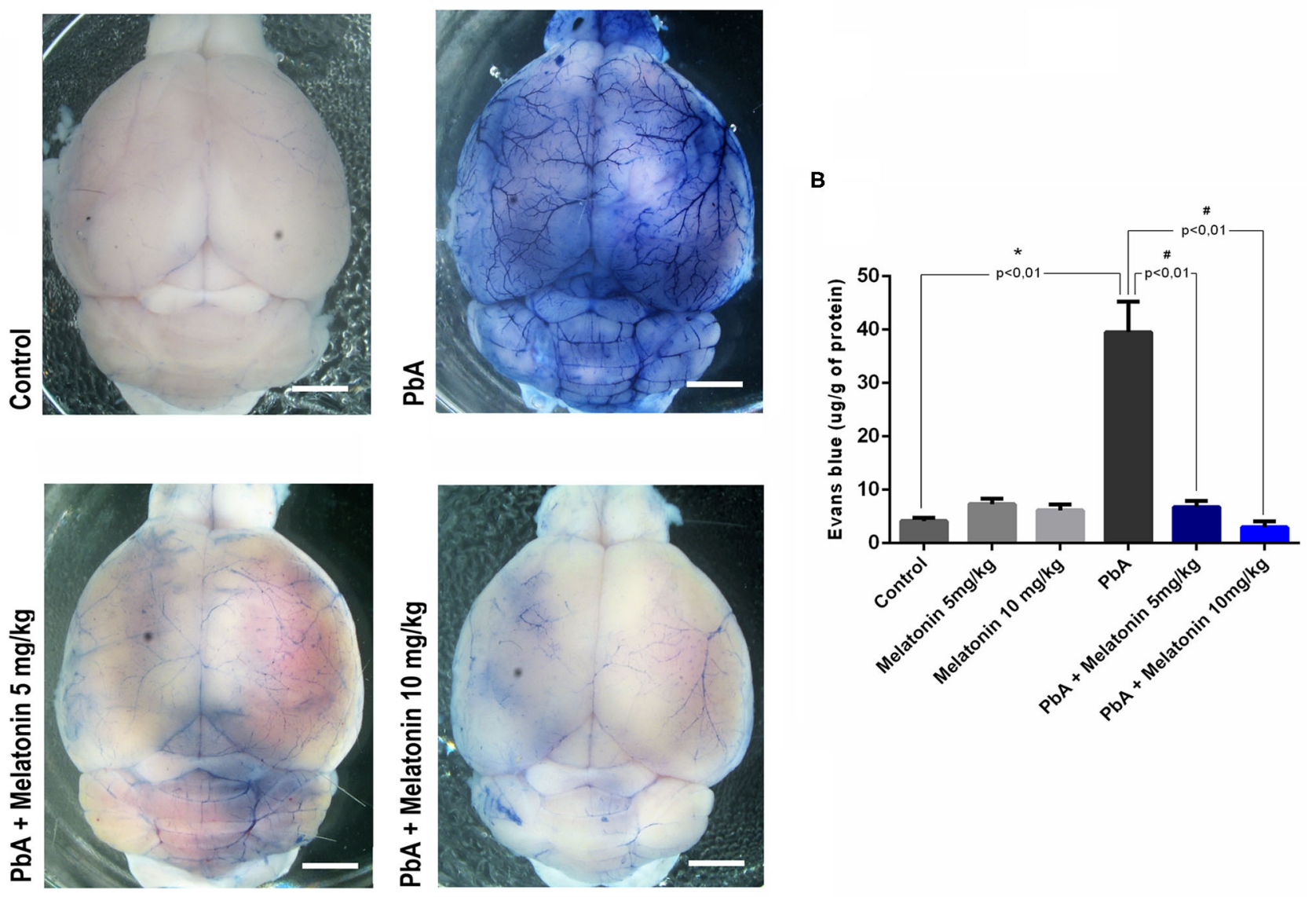

FIGURE 3 | Melatonin maintains blood-brain barrier integrity in ECM. (A) Qualitative analysis of whole brain after Evans blue dye administration in uninfected control group, PbA-infected mice, $5 \mathrm{mg} / \mathrm{kg}$ melatonin-treated PbA mice, and $10 \mathrm{mg} / \mathrm{kg}$ melatonin-treated PbA mice. Scale bars: $0.5 \mathrm{~mm}$. (B) Quantification of Evans blue (EB) extravasated into brain at 6 days post-infection. The experiment was repeated three times and subjected to one-way ANOVA and expressed as mean \pm SD $\left(n=8,{ }^{*} p<0.01\right.$ vs. control; ${ }^{\#} p<0.01$ vs. PbA).

infiltration, vascular dilatation, occluded capillaries, and hemorrhagic areas were also observed and quantified at this stage of the disease (Figures 5B,C). All these pathological changes were ameliorated by the treatment with both melatonin doses (Figures 5A,C). DAPI staining demonstrated that the number of cells was significantly reduced in the cortex of $\mathrm{PbA}$-infected mice at 6 days post-infection. In contrast, the treatment with melatonin at 5 and $10 \mathrm{mg} / \mathrm{kg}$ protected the cortical tissue from this cellular loss (Figure 6A), maintaining the number of cells near the control group (Figure 6B). Thus, we demonstrated that melatonin treatment has prevented cell loss in the brain cortex of $\mathrm{PbA}$-infected mice.

\section{Melatonin Treatment Attenuated Motor Behavioral Abnormalities Induced by PbA-Infected Mice}

To evaluate the protective effect of melatonin on motor impairment, an open field test was performed in late stage of the disease on day 6 post-infection. On the proposed test, parameters such as lines crossed, rearing, and grooming behavior were measured in the distinct groups and illustrated in Figure 7. On day 6 post-infection, $\mathrm{PbA}$-infected mice exhibited significant decreased locomotor activity and gait dysfunction by crossing a smaller number of squares as compared to uninfected mice, whereas melatonin-treated mice at different doses (5 and 10 $\mathrm{mg} / \mathrm{kg}$ ) showed a marked improvement in total locomotor activity by the increased number of crossed squares as compared to the PbA-infected mice (Figure 7A). Moreover, the uninfected group treated only with melatonin (5 and $10 \mathrm{mg} / \mathrm{kg}$ ) showed no significant behavioral alteration compared with the control group, indicating that, in this condition, melatonin did not modulate the excitability of the CNS (Figure 7).

Additional measures of motor impairment such as the number of rearing and self-grooming were also analyzed. Both parameters were also found to be significantly decreased in PbA-infected mice as compared to the uninfected control group, and melatonin elicited significant improvement in these motor indicators 


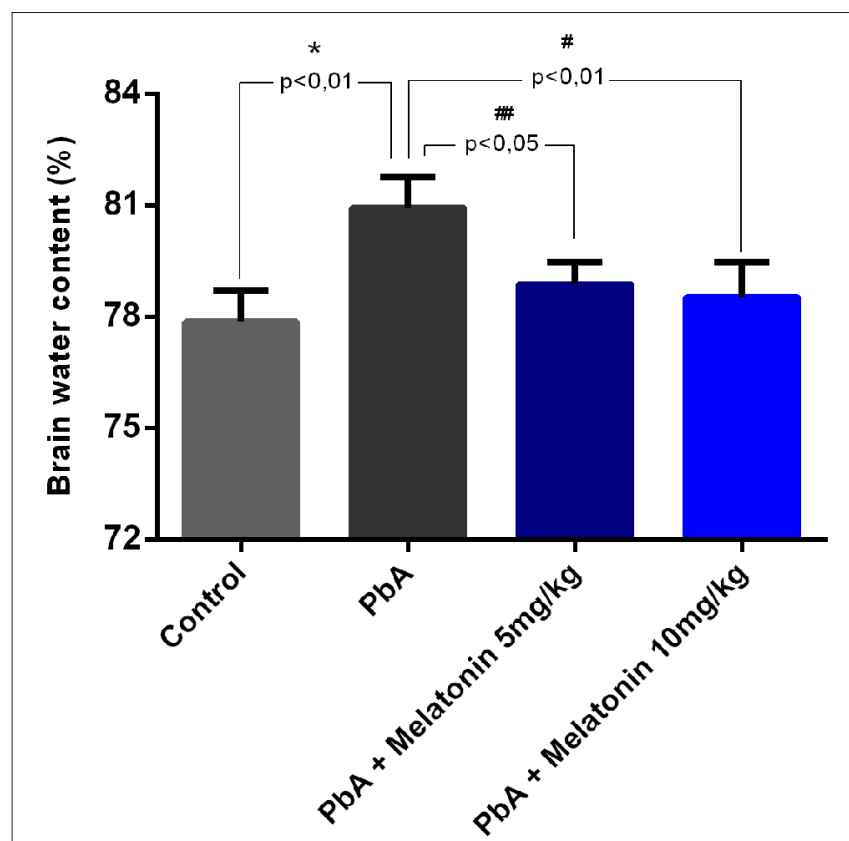

FIGURE 4 | Melatonin therapy alleviated cerebral edema in ECM. Brain water content was measured at 6 days post-infection in different groups $\left(n=8,{ }^{*} p<\right.$ 0.01 vs. control; ${ }^{\#} p<0.01$ vs. $\mathrm{PbA} ; \# p<0.05$ vs. $\left.\mathrm{PbA}\right)$.

(Figures 7B,C). Taken together, these behavioral results indicate that motor dysfunctions induced by ECM can be prevented by the treatment with melatonin.

\section{DISCUSSION}

In addition to being the main autocrine neurohormone released by pineal gland, melatonin has also been reported with antiinflammatory and antioxidant effects (Tan et al., 2003; Esposito and Cuzzocrea, 2010; Acuña-Castroviejo et al., 2014). Moreover, this neurohormone has been shown to be neuroprotective against CNS injuries by its anti-apoptotic action (Mésenge et al., 1998; Ali and Kim, 2015; Shukla et al., 2019). CM is a devastating disease often responsible for high mortality rates. Clinical studies reveal that most survivors may not fully recover from persistent motorneurocognitive impairment despite worthy recent advances in available antimalarial drugs (Murphy and Breman, 2001; Carter et al., 2005). Herein we report, for the first time, that melatonin treatment is able to ameliorate clinical signs and neurocognitive dysfunctions in $\mathrm{PbA}$-infected mice, resulting in protection from ECM outcome. Murine experimental CM is characterized by BBB breakdown, brain edema, and parenchyma lesions, which lead to damage within the CNS (Bagot et al., 2002; Martins et al., 2009a). The outcome of CM is established during the acute phase of the $\mathrm{PbA}$-infection when parasitemia reaches rates between 10 and 15\%. At this stage, mice display characteristic clinical signs such as paralysis of the limbs, poor reflex, deviation of head, spontaneous rolling over, convulsions, and coma (Ampawong et al., 2014). In addition, while PbA-infected animals presented neurological symptoms and die between days 8 and 11 post-infection, melatonin-treated mice exhibited enhanced survival from acute infection, and most of them died between 15 and 21 days post-infection with no signs of neurological dysfunction. Our results suggested that melatonin suppresses CM development, and considering that animals showed elevated levels of parasitemia in the end stage of the disease (as described in Figure 1B), melatonin-treated animals probably died of severe anemia as previously described in anterior reports (Dende et al., 2015). All of these protective effects elicited by melatonin treatment were not associated with reduction of parasitemia levels and body weight, suggesting that melatonin has exerted its protective effect mainly on the CNS of infected mice.

The fact that melatonin did not alter the parasitemia at any stage of the disease could be explained by the fact that in $P$. berghei infection, the life cycle of the parasite is not influenced by the melatonin levels developing an asynchronous pattern of infection. Bagnaresi et al. (2009) demonstrated that the inhibition of melatonin receptor and the treatment with melatonin did not modify the parasite load in the livers of mice infected with $\mathrm{PbA}$ sporozoites.

There is a sturdy connection between the breakdown of the $\mathrm{BBB}$ and $\mathrm{CM}$ pathogenesis in both human and mouse experimental models (Lou et al., 2001; Medana and Turner, 2006; Dunst et al., 2017). Moreover, cerebral edema resulting from enhanced $\mathrm{BBB}$ breakdown is also a notorious feature of HCM and ECM (Thumwood et al., 1988; Penet et al., 2005). Although parasitemia levels were relatively high in melatonintreated $\mathrm{PbA}$-infected mice, there was a relevant reduction in $\mathrm{BBB}$ leakage and brain edema after melatonin treatment on day 6 post infection. Additionally, melatonin treatment also attenuates brain histological damages induced by $\mathrm{PbA}$ infection. Although our data demonstrated that the treatment with melatonin reduces the disarrangement in the brain cortex with typical and suggestive areas of leukocyte infiltration, additional studies using CD45 and $\mathrm{CD}^{+} \mathrm{T}$ cell staining need to be performed to better characterize this effect. This provides evidence that melatonin treatment could effectively reduce brain neuroinflammation associated with ECM pathology even in the presence of elevated parasitemia levels.

Furthermore, melatonin is an amphipathic molecule, which makes it suitable to cross not only BBB but also several other cellular compartments such as endoplasmic reticulum, mitochondria, and nucleus (Guha et al., 2007; Cardinali et al., 2013; Ding et al., 2015). The mechanisms through which melatonin protects $\mathrm{BBB}$ breakdown and subsequent brain edema during CM onset might be associated with the regulation of adhesion proteins in cerebrovascular endothelial cells, although additional studies need to be done to confirm our hypothesis.

We cannot exclude the fact that melatonin neuroprotection could be associated with its antioxidant effect once previous studies have already demonstrated that daily administration of melatonin restores antioxidant capacity and inhibit the production of pro-inflammatory cytokines in an experimental model of diabetic retinopathy (Negi et al., 2011). In addition, melatonin is able to decrease the expression of NADPH oxidase isoforms Nox2 and Nox4, reduces reactive oxygen species 
A
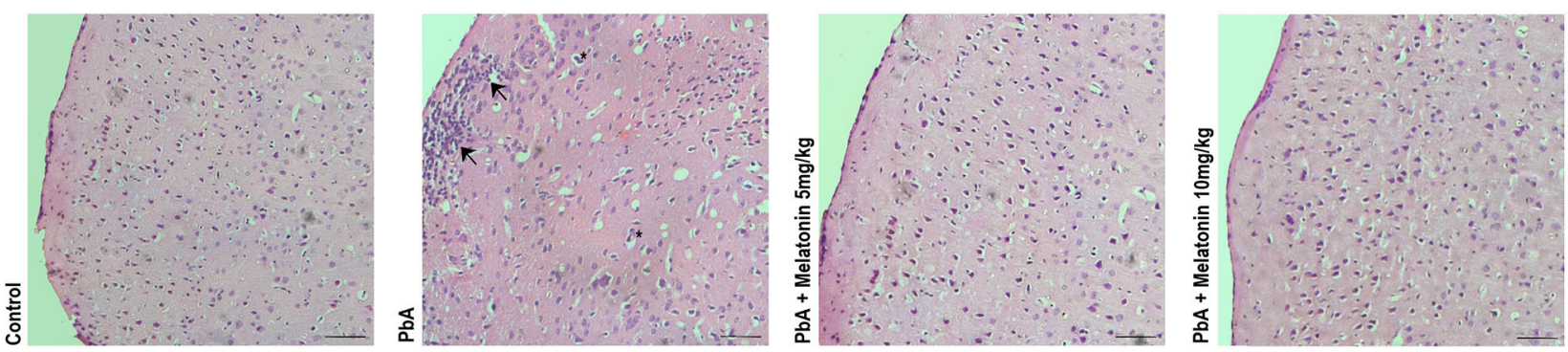

$\mathbf{B}$
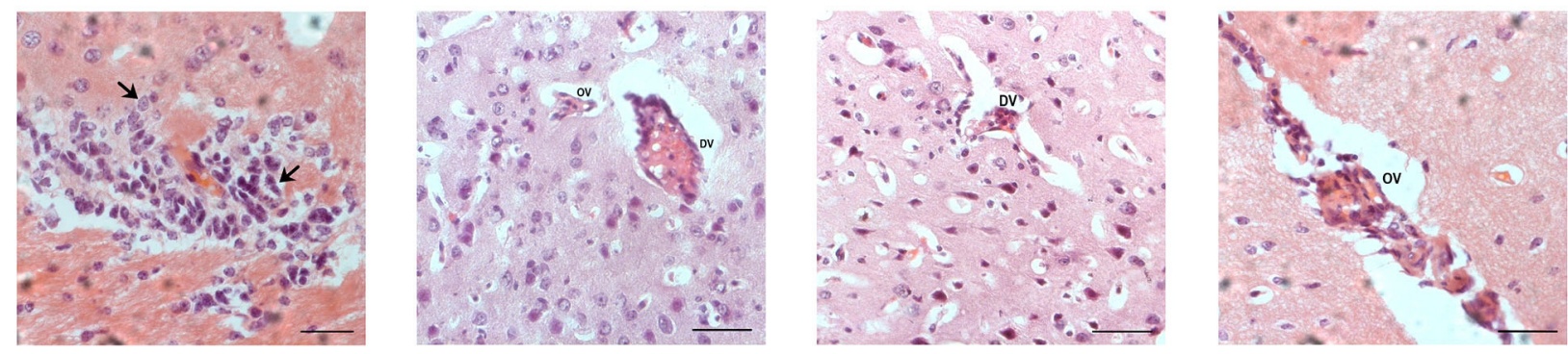

C
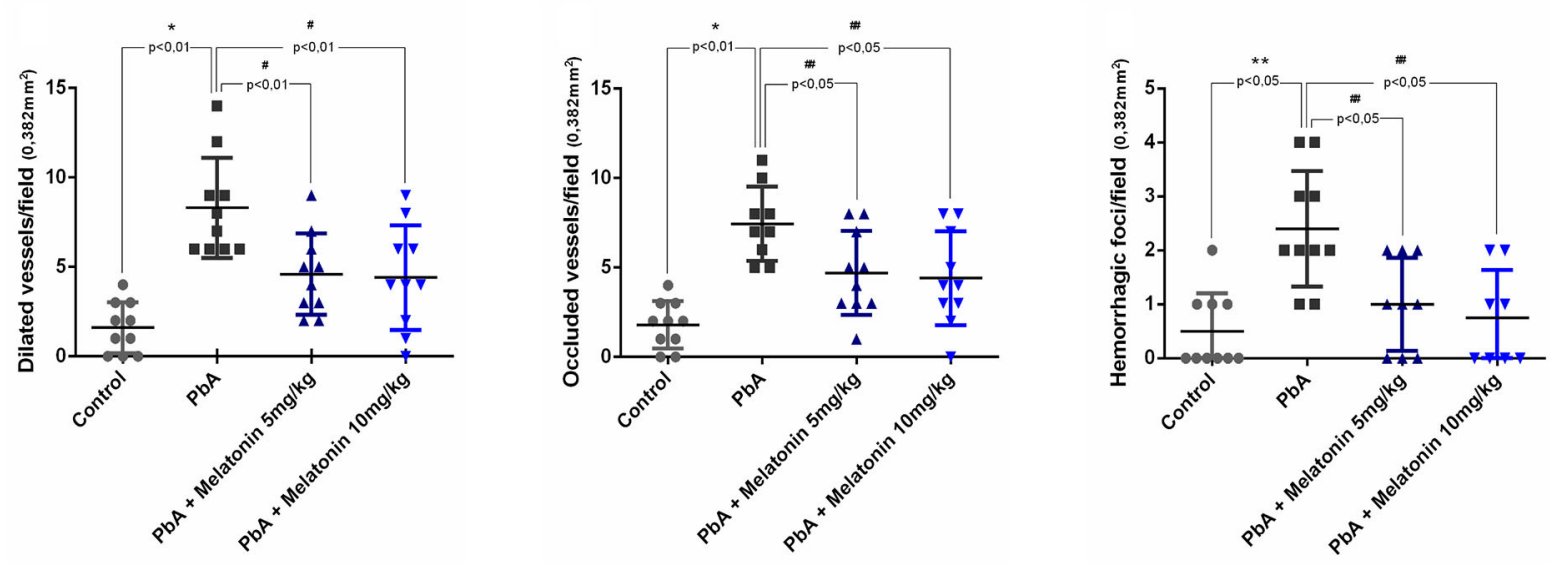

FIGURE 5 | Melatonin treatment decreases histological alteration into the brain tissue of PbA-infected mice. Representative light microphotographs from mice cerebral cortex at day 6 post-infection stained with H\&E. (A) Brain cortex from uninfected mice (control) with normal histological appearance; PbA-infected mice showing cellular infiltration (arrows) and vacuolation (asterisk); and melatonin-treated groups; $\times 20$ objective lens. (B) Brain cortex from PbA-infected mice showing infiltrated areas (arrows_ $\times 60$ objective lens), dilated vessels (DV_ $\times 40$ objective lens), and occluded vessels (OV_ $\times 60$ objective lens). (C) Data quantification of dilated vessels, occluded vessels, and hemorrhagic foci/field. Images were analyzed in a double-blind manner; $n=10$ animals/group (bars, $50 \mu \mathrm{m}) .{ }^{*} p<0.01$ vs control; ${ }^{* *} p<0.05$ vs control; $\# p<0.01$ vs PbA; \#\# $p<0.05$ vs PbA.

generation, and inhibits apoptotic cell death in a rat model of cerebral ischemia (Li et al., 2014).

In mouse models of newborn hypoxic-ischemic brain injury, melatonin exerts a neuroprotective role by the activation of M1 melatonin receptors, inhibition of mitochondrial cell death pathways, and astrocytic activation. Moreover, studies demonstrated that melatonin could potentially attenuate reactive gliosis and reduces microglial activation, which are remarkable and well-characterized events in CM pathogenesis (Cervantes et al., 2008; Sinha et al., 2017).
Besides, we also observed that melatonin treatment protected $\mathrm{CM}$ mice from long-term neurocognitive and motor impairment such as gait and motor dysfunction. The open field test is a useful method to measure poor gait and ambulation in rodent models of $\mathrm{CM}$, and in the present study, $\mathrm{PbA}$-infected mice that received melatonin performed as well as uninfected control mice. According to our behavioral analysis, melatonin significantly improved motor impairment in $\mathrm{PbA}$-infected mice. A previous report has already described that chronic melatonin therapy attenuated D-galactose-induced memory and neuronal 


\section{A}
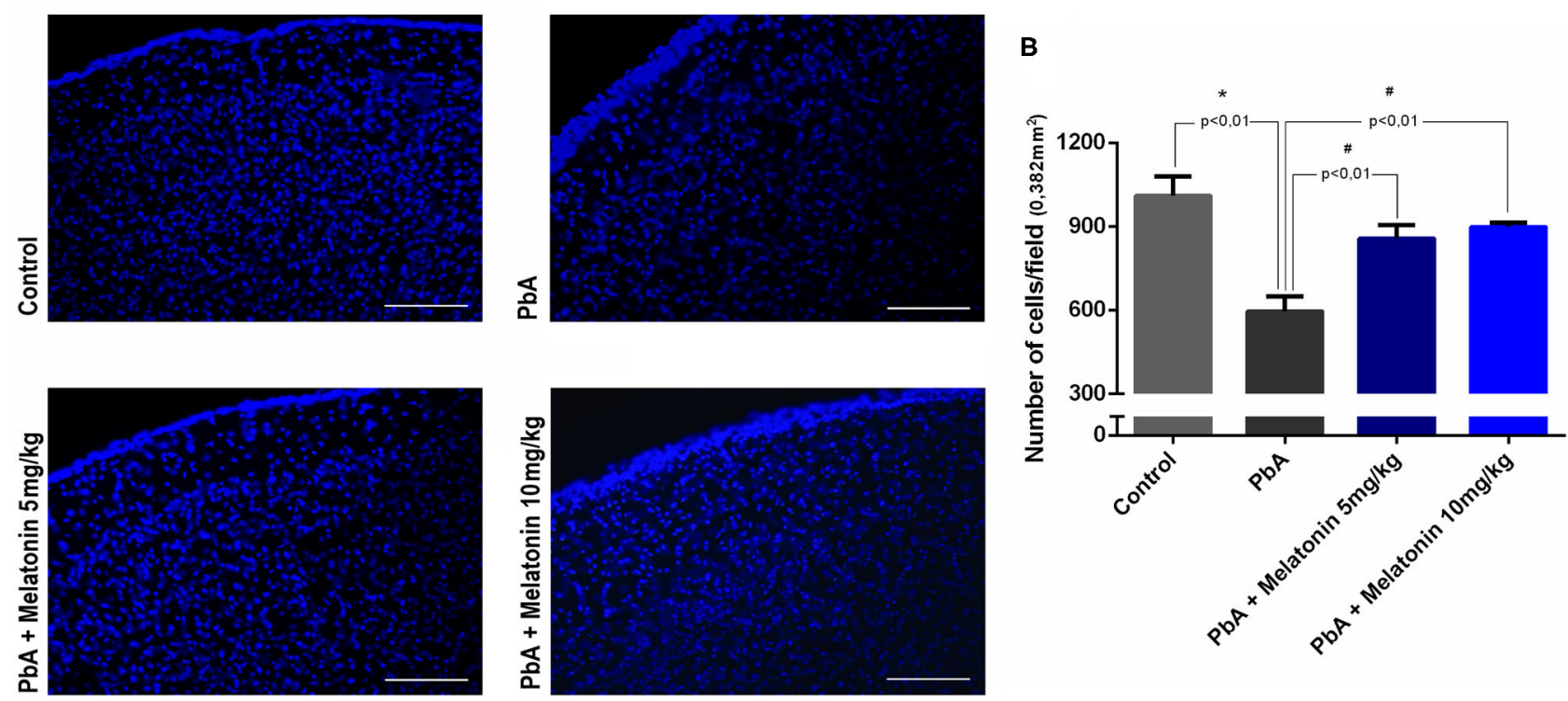

FIGURE 6 | Analysis of cell number in brain sections using DAPI staining by fluorescence microscope ( $\times 20$ objective lens). (A) The most representative fields of brain cortical area are shown (scale bar, $50 \mu \mathrm{m}$ ). (B) Quantification of DAPI nuclear stain in distinct groups using ImageJ software. Data represent mean \pm SD of three independent experiments; $n=10$ animals/group. ${ }^{*} p<0.01$ vs control; ${ }^{\#} p<0.01$ vs PbA.
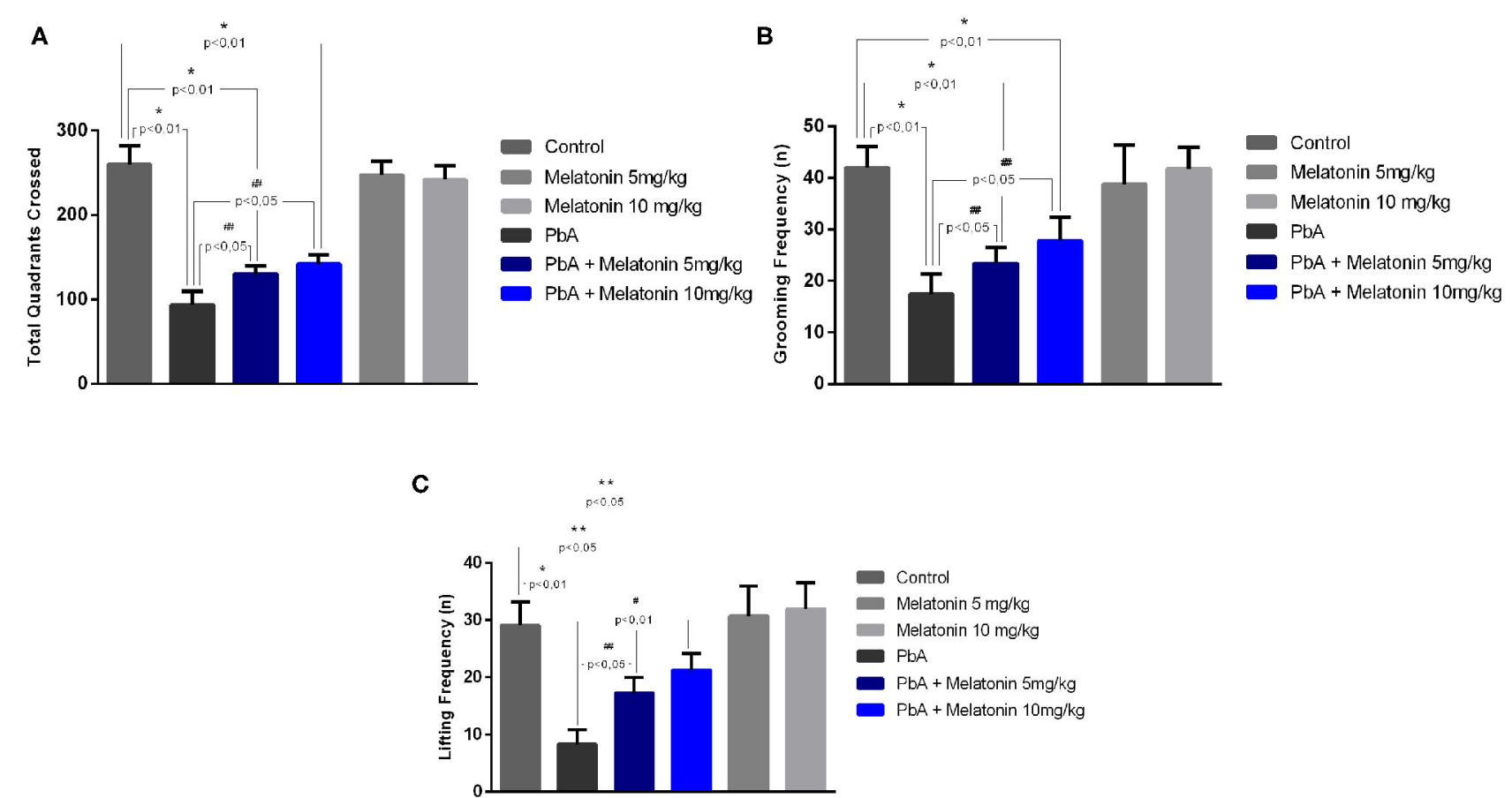

FIGURE 7 | Protective effect of melatonin against motor impairment in PbA-infected mice at 6 days post-infection. Number of crossed quadrants (A), grooming frequency (B), and lifting frequency $\mathbf{( C )}$ were recorded and quantified. The experiment was repeated three times $(n=10$ animals/group), and the values are given as the mean \pm SD. ${ }^{*} p<0.01$ vs control; ${ }^{* \star} p<0.05$ vs control; ${ }^{\#} p<0.01$ vs $\mathrm{PbA}$; $\#$ \# $p 0.05$ vs $\mathrm{PbA}$.

impairment by decreasing neurodegeneration through the activation of RAGE/NF- $\beta \beta$ and JNK signaling pathways (Ali et al., 2015).
Interestingly, a study also demonstrated that the deficiency of endogenous melatonin exacerbates the neuronal damage in traumatic brain injury patients, providing notable evidence of 
the exogenous administration efficacy. In agreement with our study, exogenous administration of melatonin by intraperitoneal injection decreases brain edema and infarct volume and ameliorates neurological deficits in mice brain injury in a single or repeated dose of $10 \mathrm{mg} / \mathrm{kg}$ (Reiter et al., 2003). Due to its functional diversity, exogenous melatonin has been investigated as a compatible candidate for the treatment of distinct disorders such as neuroinflammatory conditions and neurodegenerative diseases, but no studies have described the neuroprotective action of melatonin on the brain dysfunction induced by severe malaria (Samantaray et al., 2003; Singhal et al., 2012; Rosales-Corral et al., 2017; Su et al., 2017; Shukla et al., 2019).

In summary, our results in an experimental model of $\mathrm{CM}$ suggest that melatonin treatment may improve survival and BBB integrity and prevent neuromotor impairment in mice infected with $\mathrm{PbA}$, without altering parasitemia levels. Moreover, the exact mechanism by which melatonin exerts its neuroprotective effect should be further investigated.

\section{CONCLUSIONS}

In conclusion, the present study demonstrates for the first time the neuroprotective role of melatonin against $\mathrm{BBB}$ breakdown and behavior impairment evoked by CM. In this way, the current data represent an important further pre-clinical evidence that melatonin could be an efficient adjuvant for CM treatment.

\section{REFERENCES}

Acuña-Castroviejo, D., Escames, G., Venegas, C., Díaz-Casado, M. E., LimaCabello, E., López, L. C., et al. (2014). Extrapineal melatonin: sources, regulation, and potential functions. Cell Mol. Life Sci. 71, 2997-3025. doi: 10.1007/s00018-014-1579-2

Ali, T., Badshah, H., Kim, T. H., and Kim, M. O. (2015). Melatonin attenuates D-galactose-induced memory impairment, neuroinflammation and neurodegeneration via RAGE/NF-K B/JNK signaling pathway in aging mouse model. J. Pineal Res. 58, 71-85. doi: 10.1111/jp i. 12194

Ali, T., and Kim, M. O. (2015). Melatonin ameliorates amyloid beta-induced memory deficits, tau hyperphosphorylation and neurodegeneration via PI3/Akt/GSk3 $\beta$ pathway in the mouse hippocampus. J. Pineal Res. 59, 47-59. doi: $10.1111 /$ jpi. 12238

Ampawong, S., Chaisri, U., Viriyavejakul, P., Nontprasert, A., Grau, G. E., Pongponratn, E. (2014). Electron microscopic features of brain edema in rodent cerebral malaria in relation to glial fibrillary acidic protein expression. Int. J. Clin. Exp. Pathol. 7, 2056-2067.

Bagnaresi, P., Alves, E., Da Silva, H. B., Epiphanio, S., Mota, M. M., and Garcia, C. R. (2009). Unlike the synchronous Plasmodium falciparum and P. chabaudi infection, the $P$. berghei and $P$. yoelii asynchronous infections are not affected by melatonin. Int. J. Gen Med. 2, 47-55. doi: 10.2147\%2Fijgm.s3699

Bagot, S., Idrissa Boubou, M., Campino, S., Behrschmidt, C., Gorgette, O., Guénet, J. L., et al. (2002). Susceptibility to experimental cerebral malaria induced by Plasmodium berghei ANKA in inbred mouse strains recently derived from wild stock. Infect. Immun. 70, 2049-2056. doi: 10.1128/IAI.70.4.2049-2056.2002

Bavithra, S., Selvakumar, K., Sundareswaran, L., and Arunakaran, J. (2017). Neuroprotective effect of melatonin against PCBs induces behavioral molecular and histological changes in cerebral cortex of adult male wistar rats. Neurochem Res. 42:428. doi: 10.1007/s11064-016-2087-6

\section{DATA AVAILABILITY STATEMENT}

The raw data supporting the conclusions of this article will be made available by the authors, without undue reservation, to any qualified researcher.

\section{ETHICS STATEMENT}

The animal study was reviewed and approved by Animal Ethics Committee of the Federal University of Para (Protocol number: 6211241117/UFPA).

\section{AUTHOR CONTRIBUTIONS}

BA performed and acquired all the experimental data. NK performed the histological analyses. MT and LA performed and analyzed the behavioral data. NM performed the extravasation dye method. AP revised the manuscript and statistical analysis. SM contributed to the final drafting of the article. EB provided technical and material support. $\mathrm{AH}$ analyzed and interpreted the data. KO conceived, designed, and supervised the study.

\section{FUNDING}

This work was supported by grants from Pro-Amazônia (CAPES), CNPq, and FAPESPA, Conselho Nacional de Desenvolvimento Científico e Tecnológico- $\mathrm{CNPq}$ 311203/2017-5/FAPESPA 005/2016.
Beraldo, F. H., Almeida, F. M., da Silva, A. M., and Garcia, C. R. (2005). Cyclic AMP and calcium interplay as second messengers in melatonin-dependent regulation of Plasmodium falciparum cell cycle. J Cell Biol. 170, 551-557. doi: $10.1083 /$ jcb.200505117

Brazão, V., Colato, R. P., Santello, F. H., Filipin Mdel, V., Toldo, M. P., do Vale, G. T., et al. (2015). Interleukin-17, oxidative stress, and inflammation: role of melatonin during trypanosoma cruzi infection. J. Pineal Res. 59, 488-496. doi: $10.1111 /$ jpi.12280

Budu, A., Peres, R., Bueno, V. B., Catalani, L. H., and Garcia, C. R. D. (2007). S.N1acetyl-N2-formyl-5-methoxykynuramine modulates the cell cycle of malaria parasites. J. Pineal Res. 42, 261-266. doi: 10.1111/j.1600-079X.2006.00414.x

Cardinali, D. P., Pagano, E. S., Scacchi Bernasconi, P. A., Reynoso, R., Scacchi, P. (2013). Melatonin and mitochondrial dysfunction in the central nervous system. Horm Behav. 63, 322-330. doi: 10.1016/j.yhbeh.2012.02.020

Carroll, R. W., Wainwright, M. S., Kim, K. Y., Kidambi, T., Gómez, N. D., Taylor, T., et al. (2010). A rapid murine coma and behavior scale for quantitative assessment of murine cerebral malaria. PLOS ONE. 5:13124. doi: 10.1371/journal.pone.0013124

Carter, J. A., Ross, A. J., Neville, B. G., Obiero, E., Katana, K., Mung'alaOdera, V., et al. (2005). Developmental impairments following severe falciparum malaria in children. Trop. Med. Int. Health. 1, 3-10. doi: 10.1111/j.1365-3156.2004.01345.x

Cervantes, M., Moral,í G., Letechipía-Vallejo, G. (2008). Melatonin and ischemia-reperfusion injury of the brain. J. Pineal Res. 45, 1-7. doi: 10.1111/j.1600-079X.2007.00551.x

Chan, L. L., Wilkinson, A. R., Paradis, B. D., and Lai, N. (2012). Rapid image-based cytometry for comparison of fluorescent viability staining methods. J. Fluoresc. 22, 1301-1311. doi: 10.1007/s10895-012-1072-y

Chang, C. C., Tien, C. H., Lee, E. J., Juan, W. S., Chen, Y. H., Hung, Y. C., et al. (2012). Melatonin inhibits matrix metalloproteinase-9 (MMP9) activation in the lipopolysaccharide (LPS)-stimulated RAW 264.7 and 
BV2 cells and a mouse model of meningitis. J. Pineal Res. 53, 188-197. doi: 10.1111/j.1600-079X.2012.00986.x

Combes, V., De Souza, J. B., Rénia, L., Hunt, N. H., and Grau, G. E. (2005). Cerebral malaria: which parasite? Which model?. Drug Discov. Today Dis. Models. 2, 141-147. doi: 10.1016/j.ddmod.2005.05.015

Dai, M., Reznik, S. E., Spray, D. C., Weiss, L. M., Tanowitz, H. B., Gulinello, M., et al. (2010). Persistent cognitive and motor deficits after successful antimalarial treatment in murine cerebral malaria. Microbes Infect. 12, 1198-1207. doi: 10.1016/j.micinf.2010.08.006

Daryani, A., Montazeri, M., Pagheh, A. S., Sharif, M., Sarvi, S., Hosseinzadeh, A., et al. (2018). The potential use of melatonin to treat protozoan parasitic infections: a review. Biomed Pharmacother. 97, 948-957. doi: 10.1016/j.biopha.2017.11.007

de Souza, J. B., Hafalla, J. C., Riley, E. M., and Couper, K. N. (2009). Cerebral malaria: why experimental murine models are required to understand the pathogenesis of disease. Parasitology 137, 755-772. doi: $10.1017 /$ S0031182009991715

Dende, C., Meena, J., Nagarajan, P., Panda, A. K., Rangarajan, P. N., Padmanaban, G. (2015). Simultaneously targeting inflammatory response and parasite sequestration in brain to treat experimental cerebral malaria. Sci Rep. 5:12671. doi: $10.1038 /$ srep 12671

Desruisseaux, M. S., Gulinello, M., Smith, D. N., Lee, S. C., Tsuji, M., Weiss, L. M., et al. (2008). Cognitive dysfunction in mice infected with Plasmodium berghei strain ANKA. J. Infect. Dis. 197, 1621-1627. doi: 10.1086/587908

Ding, K., Xu, J., Wang, H., Zhang, L., Wu, Y., and Li, T. (2015). Melatonin protects the brain from apoptosis by enhancement of autophagy after traumatic brain injury in mice. Neurochem Int. 91, 46-54. doi: 10.1016/j.neuint.2015.10.008

Dunst, J., Kamena, F., Matuschewski, K. (2017). Cytokines and chemokines in cerebral malaria pathogenesis. Front Cell Infect Microbiol. 7:324. doi: $10.3389 /$ fcimb.2017.00324

Esposito, E., and Cuzzocrea, S. (2010). Antiinflammatory activity of melatonin in central nervous system. Curr. Neuropharmacol. 8, 228-242. doi: 10.2174/157015910792246155

Fischer, T. W., Kleszczyński, K., Hardkop, L. H., Kruse, N., and Zillikens, D. (2013). Melatonin enhances antioxidative enzyme gene expression (CAT, GPx, SOD), prevents their UVR-induced depletion, and protects against the formation of DNA damage (8-hydroxy-2'-deoxyguanosine) in ex vivo human skin. J. Pineal Res. 54, 303-312. doi: 10.1111/jpi.12018

Guha, M., Maity, P., Choubey, V., Mitra, K., Reiter, R. J., Bandyopadhyay, U. (2007). Melatonin inhibits free radical-mediated mitochondrial-dependent hepatocyte apoptosis and liver damage induced during malarial infection. J. Pineal Res. 43, 372-381. doi: 10.1111/j.1600-079X.2007.00488.x

He, P., Ouyang, X., Zhou, S., Yin, W., Tang, C., Laudon, M., et al. (2013). A novel melatonin agonist Neu-P11 facilitates memory performance and improves cognitive impairment in a rat model of Alzheimer' disease. Horm Behav. 64, 1-7. doi: 10.1016/j.yhbeh.2013.04.009

Hunt, N. H., Golenser, J., Chan-Ling, T., Parekh, S., Rae, C., Potter, S., et al. (2006). Immunopathogenesis of Cerebral Malaria. 36, 569-582. doi: 10.1016/j.ijpara.2006.02.016

Hunt, N. H., and Grau, G. E. (2003). Cytokines: accelerators and brakes in the pathogenesis of cerebral malaria. Trends Immunol. 24, 491-499. doi: 10.1016/S1471-4906(03)00229-1

Idro, R., Jenkins, N. E., and Newton, C. R. (2005). Pathogenesis, clinical features, and neurological outcome of cerebral malaria. Lancet Neurol. 4, 827-840. doi: 10.1016/S1474-4422(05)70247-7

Jimenez-Jorge, S., Guerrero, J. M., Jimenez-Caliani, A. J., Naranjo, M. C., Lardone, P. J., Carrillo-Vico, A., et al. (2007). Evidence for melatonin synthesis in the rat brain during development. J. Pineal Res. 42, 240-246. doi: 10.1111/j.1600-079X.2006.00411.x

John, C. C., Bangirana, P., Byarugaba, J., Opoka, R. O., Idro, R., Jurek, A. M., et al. (2008). Cerebral malaria in children is associated with long-term cognitive impairment. Pediatrics 122, 92-99. doi: 10.1542/peds.2007-3709

Kim, H., Erdman, L. K., Lu, Z., Serghides, L., Zhong, K., Dhabangi, A., et al. (2014). Functional roles for C5a and C5aR but no C5L2 in the pathogenesis of human and experimental cerebral malaria. Infect Immun. 82, 371-379. doi: 10.1128/IAI.01246-13

Li, H., Wang, Y., Feng, D., Liu, Y., Xu, M., Gao, A., et al. (2014). Alterations in the time course of expression of the Nox family in the brain in a rat experimental cerebral ischemia and reperfusion model: effects of melatonin. J. Pineal Res. 57, 110-119. doi: 10.1111/jpi.12148

Lou, J., Lucas, R., Grau, G. E. (2001). Pathogenesis of cerebral malaria: recent experimental data and possible applications for humans. Clin. Microbiol. Rev. 14, 810-820. doi: 10.1128/CMR.14.4.810-820.2001

Luthra, T., Nayak, A. K., Bose, S., Chakrabarti, S., Gupta, A., and Sen, S. (2019). Indole based antimalarial compounds targeting the melatonin pathway: their design, synthesis and biological evaluation. Eur. J. Med. Chem. 168, 11-27. doi: 10.1016/j.ejmech.2019.02.019

Martins, Y. C., Carvalho, L. J., and Daniel-Ribeiro, C. (2009a). Challenges in the determination of early predictors of cerebral malaria: Lessons from the human disease and the experimental murine models. Neuroimmunomodulation 16, 134-145. doi: 10.1159/000180268

Martins, Y. C., Smith, M. J., Pelajo-Machado, M., Werneck, G. L., Lenzi, H. L., Daniel-Ribeiro, C. T., et al. (2009b). Characterization of cerebral malaria in the outbred swiss webster mouse infected by Plasmodium berghei ANKA. Int. J. Exp. Pathol. 90, 119-130. doi: 10.1111/j.1365-2613.2008.00622.x

Medana, I. M., and Turner, G. D. (2006). Human cerebral malaria and the bloodbrain barrier. Int. J. Parasitol. 36, 555-568. doi: 10.1016/j.ijpara.2006.02.004

Mésenge, C., Margaill, I., Verrecchia, C., Allix, M., Boulu, R. G., and Plotkine, M. (1998). Protective effect of melatonin in a model of traumatic brain injury in mice. J. Pineal Res. 25, 41-46. doi: 10.1111/j.1600-079X.1998.tb00384.x

Murphy, S. C., and Breman, J. G. (2001). Gaps in the childhood malaria burden in Africa: cerebral malaria, neurological sequelae, anemia, respiratory distress, hypoglycemia, and complications of pregnancy. Am. J. Trop. Med. Hyg. 64, 57-67. doi: 10.4269/ajtmh.2001.64.57

Negi, G., Kumar, A., and Sharma, S. S. (2011). Melatonin modulates neuroinflammation and oxidative stress in experimental diabetic neuropathy: effects on NF-kappaB and Nrf2 cascades. J. Pineal Res. 50, 124-131. doi: 10.1111/j.1600-079X.2010.00821.x

Oliveira, K. R. H. M., Kauffmann, N., Leão, L. K. R., Passos, A. C. F., Rocha, F. A. F., Herculano, A. M., et al. (2017). Cerebral malaria induces electrophysiological and neurochemical impairment in mice retinal tissue: possible effect on glutathione and glutamatergic system. Malar J. 16:440. doi: 10.1186/s12936-017-2083-6

Penet, M. F., Viola, A., Confort-Gouny, S., Le Fur, Y., Duhamel, G., Kober, F., et al. (2005). Imaging experimental cerebral malaria in vivo: significant role of ischemic brain edema. J. Neurosci. 25, 7352-7358. doi: 10.1523/JNEUROSCI.1002-05.2005

Radogna, F., Diederich, M., and Ghibelli, L. (2010). Melatonin: a pleiotropic molecule regulating inflammation. Biochem. Pharmacol. 80, 1844-1852. doi: 10.1016/j.bcp.2010.07.041

Reiter, R. J., Sainz, R. M., Lopez-Burillo, S., Mayo, J. C., Manchester, L. C., and Tan, D. X. (2003). Melatonin ameliorates neurologic damage and neurophysiologic deficits in experimental models of stroke. Ann N. Y. Acad. Sci. (2003) 993, 35-47. doi: 10.1111/j.1749-6632.2003.tb07509.x

Rénia, L., Howland, S. W., Claser, C., Charlotte-Gruner, A., Suwanarus, R., HuiTeo, T., et al. (2012). Cerebral malaria: mysteries at the blood-brain barrier. Virulence 3, 193-201. doi: 10.4161/viru.19013

Rodriguez, C., Mayo, J. C., Sainz, R. M., Antolín, I., Herrera, F., Martín, V., et al. (2004). Regulation of antioxidant enzymes: a significant role for melatonin. J. Pineal Res. 36, 1-9. doi: 10.1046/j.1600-079X.2003.00092.x

Rosales-Corral, S. A., Acuña-Castroviejo, D., Coto-Montes, A., Boga, J. A., Manchester, L. C., Fuentes-Broto, L., et al. (2017). Alzheimer's disease: pathological mechanisms and the beneficial role of melatonin. J. Pineal Res. 52, 167-202. doi: 10.1111/j.1600-079X.2011.00937.x

Rudnitskaya, E. A., Muraleva, N. A., Maksimova, K. Y., Kiseleva, E., Kolosova, N. G., and Stefanova, N. A. (2015). Melatonin attenuates memory impairment, amyloid- $\beta$ accumulation, and neurodegeneration in a rat model of sporadic alzheimer's disease. J. Alzheimers Dis. 47, 103-116. doi: 10.3233/JAD-150161

Samantaray, S., Das, A., Thakore, N. P., Matzelle, D. D., Reiter, R. J., Ray, S. K., et al. (2003). Therapeutic potential of melatonin in traumatic central nervous system injury. J. Pineal Res. 47, 134-142. doi: 10.1111/j.1600-079X.2009.00703.x

Schuck, D. C., Jordão, A. K., Nakabashi, M., Cunha, A. C., Ferreira, V. F., and Garcia, C. R. (2014). Synthetic indole and melatonin derivatives exhibit antimalarial activity on the cell cycle of the human malaria parasite Plasmodium falciparum. Eur. J. Med. Chem. 78, 375-382. doi: 10.1016/j.ejmech.201 4.03.055 
Shukla, M., Chinchalongporn, V., Govitrapong, P., and Reiter, R. J. (2019). The role of melatonin in targeting cell signaling pathways in neurodegeneration. Ann. N. Y. Acad. Sci. 1443, 75-96. doi: 10.1111/nyas.14005

Singhal, N. K., Srivastava, G., Agrawal, S., Jain, S. K., and Singh, M. P. (2012). Melatonin as a neuroprotective agent in the rodent models of Parkinson's disease: is it all set to irrefutable clinical translation?. Mol. Neurobiol. 45, 186-199. doi: 10.1007/s12035-011-8225-X

Sinha, B., Wu, Q., Li, W., Tu, Y., Sirianni, A. C., Chen, Y., et al. (2017). Protection of melatonin in experimental models of newborn hypoxic-ischemic brain injury through MT1 receptor. J. Pineal. Res. 64:e12443. doi: 10.1111/jpi.12443

Su, S. C., Hsieh, M. J., Yang, W. E., Chung, W. H., Reiter, R. J., and Yang, S. F. (2017). Cancer metastasis: mechanisms of inhibition by melatonin. J. Pineal Res. 62:e12370. doi: 10.1111/jpi.12370

Tan, D. X., Manchester, L. C., Hardeland, R., Lopez-Burillo, S., Mayo, J. C., Sainz, R. M., et al. (2003). Melatonin: a hormone, a tissue factor, an autocoid, a paracoid, and an antioxidant vitamin. J. Pineal Res. 34, 75-78. doi: 10.1034/j.1600-079X.2003.02111.X

Thumwood, C. M., Hunt, N. H., Clark, I. A., and Cowden, W. B. (1988). Breakdown of the blood-brain barrier in murine cerebral malaria. Parasitology 96, 579-589. doi: 10.1017/S0031182000080203
Wang, X., Sirianni, A., Pei, Z., Cormier, K., Smith, K., Jiang, J., et al. (2011). The melatonin MT1 receptor axis modulates mutant Huntingtin-mediated toxicity. J. Neurosci. 31, 14496-14507. doi: 10.1523/JNEUROSCI.3059-11.2011

WHO (2000). World Malaria Report. World Health Organization. WHO (2017). World Malaria Report. World Health Organization.

Zhang, H. M., and Zhang, Y. (2014). Melatonin: a well-documented antioxidant with conditional pro-oxidant actions. J. Pineal. Res. 57, 131-146. doi: $10.1111 /$ jpi.12162

Conflict of Interest: The authors declare that the research was conducted in the absence of any commercial or financial relationships that could be construed as a potential conflict of interest.

Copyright (C) 2020 Ataide, Kauffmann, Mendes, Torres, dos Anjos, Passos, de Moraes, Batista, Herculano and Oliveira. This is an open-access article distributed under the terms of the Creative Commons Attribution License (CC BY). The use, distribution or reproduction in other forums is permitted, provided the original author(s) and the copyright owner(s) are credited and that the original publication in this journal is cited, in accordance with accepted academic practice. No use, distribution or reproduction is permitted which does not comply with these terms. 